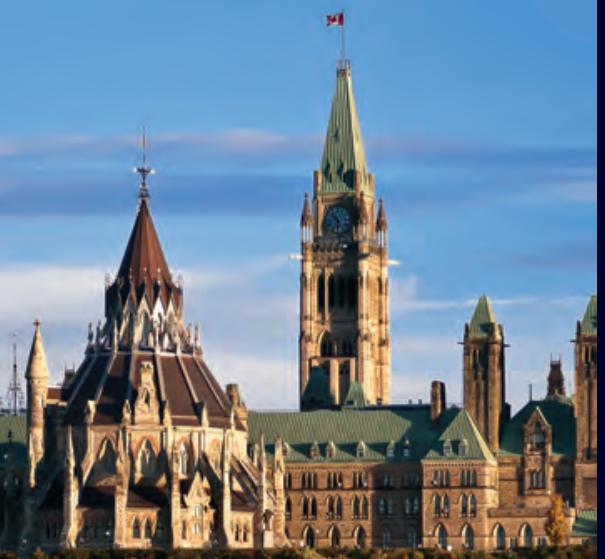

institut C.D. HOWE institute

\author{
COMMENTARY
}

NO. 479

\title{
How to Restore Public Trust and Credibility at the National Energy Board
}

Ottawa is committed to making the NEB a modern, efficient and effective energy regulator. Enhancing its independence, conflict of interest rules and transparency will be vital. 


\section{THE C.D. HOWE INSTITUTE'S COMMITMENT TO QUALITY, INDEPENDENCE AND NONPARTISANSHIP}

ABOUT THE AUTHOR

Lesley Matthews is Principal, Polaris

Solutions Inc.
Commentary No. 479

May 2017

Energy and Natural

RESOURCES
$\$ 12.00$

ISBN 978-1-987983-29-6

ISSN 0824-8001 (print);

ISSN 1703-0765 (online)
The C.D. Howe Institute's reputation for quality, integrity and nonpartisanship is its chief asset.

Its books, Commentaries and E-Briefs undergo a rigorous two-stage review by internal staff, and by outside academics and independent experts. The Institute publishes only studies that meet its standards for analytical soundness, factual accuracy and policy relevance. It subjects its review and publication process to an annual audit by external experts.

As a registered Canadian charity, the C.D. Howe Institute accepts donations to further its mission from individuals, private and public organizations, and charitable foundations. It accepts no donation that stipulates a predetermined result or otherwise inhibits the independence of its staff and authors. The Institute requires that its authors publicly disclose any actual or potential conflicts of interest of which they are aware. Institute staff members are subject to a strict conflict of interest policy.

C.D. Howe Institute staff and authors provide policy research and commentary on a non-exclusive basis. No Institute publication or statement will endorse any political party, elected official or candidate for elected office. The Institute does not take corporate positions on policy matters.
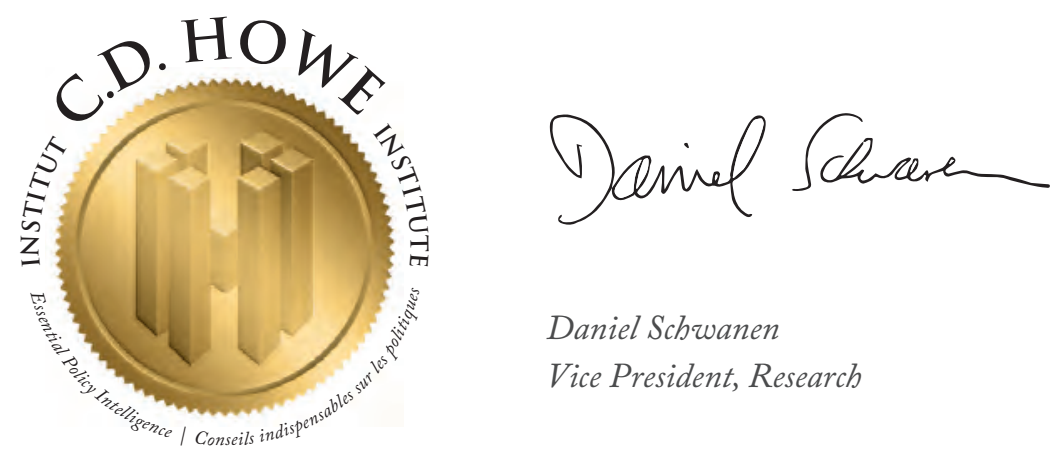

Daniel Schwanen

Vice President, Research 


\section{THE STUDY IN BRIEF}

In November 2016 Natural Resources Minister Jim Carr struck an expert panel to conduct a public review of the NEB in an effort to "position the NEB as a modern, efficient, and effective energy regulator" to regain the board's public credibility and trust that has eroded over the past decade.

This Commentary looks at whether the NEB is "broken" by evaluating its performance against six recognized attributes of an effective and efficient regulator, including: independence, conflict-of-interest protection, transparent and inclusive processes, performance management and adaptability, capacity, and enabling factors. As a result, the Commentary makes 23 recommendations intended to assist the NEB, as well as the federal government, in improving the effectiveness and efficiency of federal energy regulation in Canada.

Among the key recommendations:

The federal government should restore the independence of the NEB's decisionmaking authority for pipeline applications, eliminating political overrides of NEB decisions except via courts. To keep the review process timely, review participants should be limited to those directly affected or have relevant expertise related to the project under review. However, the federal government should rescind the onesize-fits-all time-limit requirements on NEB reviews and instead require each panel to determine the timeline for each review. NEB hearings are also not the appropriate venue for ongoing engagement with local and Aboriginal communities. The government should implement such a mechanism outside of the formal hearing process.

To reduce the perception of a conflict of interest, the NEB should review its staff Code of Conduct to ensure it covers all situations potentially creating a conflict of interest. Ottawa should also make sure that the NEB has the capacity to attract the best candidates for its needs and that it transparently evaluates its overarching regulatory goals. Lastly, the government should more clearly articulate how it defines the broader public interest that the NEB strives to achieve in its regulatory process.

It is in the shared interest of all Canadians to have trust in institutions whose decisions will shape the next steps in Canada's energy future. The work of a regulator such as the NEB is difficult, complex and often thankless. Effective and efficient regulatory institutions are a necessary part of a functioning democracy. While regulators are not elected officials, they do the work delegated to them by elected politicians. Ideally, a policy framework should guide their decisions.

For the NEB to function as an effective and efficient regulator, its recommendations and decisions need to be guided by a transparent policy framework for energy development that is reconciled with the many other aspects of the public interest. The path to this framework will not be easy and not everyone will agree on the outcomes. However, the work is necessary to re-establish the NEB as a credible, effective and efficient energy regulator.

C.D. Howe Institute Commentary $(\mathrm{C}$ is a periodic analysis of, and commentary on, current public policy issues. Michael Benedict and James Fleming edited the manuscript; Yang Zhao prepared it for publication. As with all Institute publications, the views expressed here are those of the author and do not necessarily reflect the opinions of the Institute's members or Board of Directors. Quotation with appropriate credit is permissible.

To order this publication please contact: the C.D. Howe Institute, 67 Yonge St., Suite 300, Toronto, Ontario M5E 1J8. The full text of this publication is also available on the Institute's website at www.cdhowe.org. 


\section{Following the Liberal party's election in November 2015, Prime Minister Justin Trudeau delivered letters to each of his cabinet ministers, defining their mandates and priorities.}

In his letter to Natural Resources Minister Jim Carr, the Prime Minister signalled the intent to “...modernize the National Energy Board to ensure that its composition reflects regional views and has sufficient expertise in fields such as environmental science, community development and indigenous traditional knowledge (Office of the Prime Minister 2015).”

A year later, on Nov. 8, 2016, Carr announced a five-member expert panel to undertake a public review of the National Energy Board (NEB), an effort aimed to "position the NEB as a modern, efficient, and effective energy regulator" to regain the board's public credibility and trust that has eroded over the past decade (Government of Canada 2016c). Meanwhile, the NEB itself has undertaken increased efforts to improve its processes so as to "regain public trust (NEB 2016a).”

This Commentary examines whether the NEB is "broken" by evaluating its performance against six widely recognized attributes of an effective and efficient regulator: independence, conflict-of-interest protection, transparent and inclusive processes, performance management and adaptability, capacity, and enabling factors. As a result, the Commentary makes 23 recommendations intended to assist the NEB, as well as the federal government, in improving the effectiveness and efficiency of federal energy regulation in Canada. Recommendation highlights are:

- Independence: the federal government should restore the functional independence of the NEB by rescinding 2012 changes to the National Energy Board Act related to its decisionmaking role and to legislated timelines.

- Conflict of interest: the NEB should review its staff Code of Conduct to ensure all situations potentially creating a conflict of interest are addressed. The federal government should review, and possibly update, its hiring processes for board members to ensure the same.

- Transparent and inclusive processes: The NEB should implement a mechanism for ongoing engagement with local and Aboriginal communities, outside of the formal hearing process.

- Performance management and adaptability: The NEB should ensure the programs within its Departmental Results Framework are independently and regularly evaluated.

- Capacity: The NEB and the federal government should ensure there are no barriers preventing the NEB from attracting experienced candidates to permanent staff roles or for short-term contracts.

The author thanks Benjamin Dachis, Joseph Doucet, the Energy Policy Council of the C.D. Howe Institute, and anonymous reviewers for comments on an earlier draft. She retains responsibility for the views expressed here. Lesley Matthews owns Polaris Solutions Inc., which provides regulatory advice to the energy industry and government agencies. Matthews previously worked for the NEB (2003-2008) and was contracted to Kinder Morgan Canada Inc. for the NEB's review of its Trans Mountain Expansion Project. To prepare this Commentary, Matthews conducted nine interviews with people who have expertise related to the NEB, including former NEB members, a legal expert, former interveners and expert witnesses in recent NEB reviews, senior-level staff with experience in NEB processes at NEBregulated Group 1 pipeline companies (i.e., companies that own/operate large pipeline transmission systems in Canada) as well as senior-level federal government staff. A copy of the interview guide is provided in online Appendix 1. Matthews thanks all of the people who participated in the interviews that helped inform the development of this Commentary. 
- Enabling factors: the federal government, in partnership with the provinces and territories, should establish an integrated energy strategy reflecting the public interest of Canada, within which the NEB's work would be framed.

\section{IS THE NEB BROKEN?}

Resource development and energy infrastructure projects in Canada have faced increasingly intense public scrutiny and opposition for more than a decade (Zilnik and Switzer 2015). By extension, the NEB's processes and decisions have also faced increased criticism and legal challenges. ${ }^{1}$ (See Box 1 for an introduction on the roles of the NEB).

It is difficult to pinpoint when and how all the NEB pushback began. Zilnik and Switzer (2015) describe how environmental groups began intervening in the public reviews of oil-sands projects in the early 2000s, at a time when Canada's commitment to reduce greenhouse gas (GHG) emissions was juxtaposed with then Prime Minister Stephen Harper's ambition for Canada to be an "emerging energy superpower (Taber 2006)." Harper's ambition persisted through policies reflected in his nearly a decade in office, from 2006 to 2015. Zilnik and Switzer further describe how, during this period, environmentalists shifted their opposition from the review of oil-sands projects to the enabling infrastructure required to support oil-sands development - pipelines. This shift in strategy included interventions in the US review of the Keystone XL Pipeline Project, as well as in Canadian reviews of Enbridge's Northern Gateway Project, Enbridge Line 9 Project, Enbridge Line 3 Replacement Project and, most recently, the Kinder Morgan Canada Inc. Trans Mountain Expansion Project.

The previous federal government's seeming reluctance to consider differing viewpoints on energy development eroded its relationship with members of the public who challenged proposed resource and pipeline developments in light of Canada's waning climate-change commitments (Colton et al. 2016). Furthermore, Bill C-38, introduced in 2012, made substantial changes to the federal environmental assessment process, the National Energy Board Act, the federal Fisheries Act and the Navigable Waters Protection Act. These changes produced a public perception that certain environmental protections and environmental review processes had been diminished to make way for expedited approvals of energy infrastructure (Colton et al. 2016).

At the same time, a few notable energy infrastructure failures underscored the public's diminishing trust in governments' ability to protect public health and safety. ${ }^{2}$ These incidents included the massive BP Deepwater Horizon blowout in the Gulf of Mexico (April 2010), the Enbridge Kalamazoo River oil spill in Michigan (July 2010), the natural gas pipeline explosion in San Bruno,

1 See the NEB's website for a list of recent and current court challenges to its decisions: http://www.neb-one.gc.ca/ pplctnflng/crt/index-eng.html.

2 This statement reflects a global trend in declining trust in government. Each year, international consulting firm Edelman publishes a Trust Barometer, a credibility survey of thousands of respondents (both mass and informed public) on feelings of trust in government, media, business and non-governmental organizations. In Canada, the mass population's feelings of trust toward government declined from 2012-2017 with a small uptick in 2015/16 (see Global Results starting in 2012 here and the most recent 2017 Global Results). Between 2016 and 2017, Canadian respondents recorded a decline in trust for government officials/regulators (see 2017 Global Results). In 2013/14, Edelman reported a low feeling of trust globally in government's ability to oversee businesses, make ethical and moral decisions and to solve social issues (see 2013 Global Results and 2014 Global Results).With respect to the NEB specifically, a 2016 Ekos poll found that just over half of all Canadians had little or no confidence in the NEB. 


\section{Box 1: Introduction to the NEB}

The NEB's mandate is to promote safety and security, environmental protection, and efficient energy infrastructure and markets in the Canadian public interest through regulating the:

- Construction and operation of oil, natural gas and commodity pipelines and power lines that are interprovincial or international, including the setting of pipeline tolls and tariffs;

- Import and export of natural gas;

- Export of oil and electrical power; and

- Exploration and development of oil and natural gas in frontier areas, including offshore, not covered by provincial-federal accords (Newfoundland and Labrador and Nova Scotia currently have accords) or devolution agreements with territories.

The NEB is a federal quasi-judicial tribunal that acts at arm's length from the Minister of Natural Resources Canada and reports to Parliament through the minister. The minister is responsible for recommending to the federal cabinet whether the NEB should issue approval certificates for major pipelines and power lines, licences for the export and import of gas and the export of oil, and any variances to these certificates and licences. The minister also recommends to cabinet potential NEB board members and may ask the NEB for advice on energy matters. Furthermore, the minister also has obligations to appoint an arbitration committee or negotiator to settle compensation disputes between landowners and pipeline companies over access to land or for damages.

The NEB has nine permanent members and about 500 full-time staff in Calgary (head office), Vancouver, Montreal and Yellowknife. The NEB's mandate is enabled by several pieces of legislation including the National Energy Board Act, the Canadian Oil and Gas Operations Act, the Oil and Gas Operations Act, the Canada Petroleum Resources Act and the Petroleum Resources Act.

Calif. (September 2010) and the tragic LacMégantic derailment in Quebec, killing 47 people (2013). Although none of these disasters were related to energy infrastructure regulated by the NEB, certain segments of the public grew skeptical about the safety of hydrocarbon transportation and energy regulators' abilities to properly regulate the oil and gas industry.

The focus sharpened in the 2014-2016 period when the Harper government and the NEB itself took actions that were perceived to further undermine the energy regulator's credibility and processes. These actions included:

- In April 2014, the NEB Panel for the review of the proposed Trans Mountain Expansion Project from Alberta to $\mathrm{BC}$ decided against including oral cross-examination to test the evidentiary record. While it is not mandatory to include oral cross-examination and not all past proceedings have included it, the Trans Mountain Expansion Project review is thought to be the first NEB review of a major, controversial project that did not include oral cross-examination. Some interveners were outraged and felt that the evidence could not, therefore, be properly tested (NEB 2014).

- In July 2015, the government appointed energy consultant Steven Kelly to the NEB board. At the time (and during cabinet's review of his application), Kelly was an expert witness for Trans Mountain proponent Kinder Morgan Canada Inc., having prepared evidence on the expansion project's economic feasibility before the NEB. As a result of Kelly's appointment and his apparent conflict of interest, his evidence was struck from the NEB's record, and the review was delayed until Kinder Morgan could replace the evidence and it could be tested by the interveners (NEB 2015b). 
- In August/September 2016, a news report alleged three NEB board members, including two members of the panel reviewing TransCanada's Energy East Pipeline Project, along with the NEB chairperson, met privately in early 2015 with Jean Charest, then lobbying on behalf of TransCanada. The three declared they were unaware of the contractual relationship between Charest and TransCanada at the time of the meeting. As a result of an intervener motion requesting the recusal of the panel and due to a reasonable apprehension of bias, the threemember panel stepped down in September 2016 and the review was put on hold (NEB 2016a).

As well, in 2014, the federal Office of the Auditor General (OAG) released a report from the Commissioner of the Environment and Sustainable Development (CESD) that included four recommendations on how the NEB could improve its implementation of the Canadian Environmental Assessment Act, 2012. The OAG followed up a year later with another CESD report outlining various findings and recommendations to improve the NEB's oversight of federally regulated pipelines. Although none of the OAG's findings and recommendations was an indictment of a failed regulator, the timing of the reports ratcheted up scrutiny of the NEB's performance.

The confluence of these events translated into vocal public groups deeming the NEB not credible and as untrustworthy. Criticism of the NEB and its processes is not new, nor are the NEB's and the federal government's efforts to improve the regulatory framework for energy development (National Energy Board 1988; NEB 2016a; NEB 2016d; NEB 2016e; NEB 2016f). However, the question remains, do these improvements mean the NEB is a "modern" and, by corollary, an effective and efficient, regulator? ${ }^{3}$ Indeed, what does it mean to be an effective and efficient energy regulator?

\section{WHAT MAKES AN ENERGY REGULATOR EFFECTIVE AND EFFICIENT?}

There are many ways to characterize and categorize the attributes of an effective and efficient regulator. ${ }^{4}$ The following six sub-sections discuss certain attributes of regulatory effectiveness and efficiency, how they are relevant to the criticisms the NEB faces today and how it has measured up against these attributes. As a result, the ensuing recommendations are directed to the NEB and/or the federal government. ${ }^{5}$ The author designed these recommendations to be considered as a whole and not individually, as they are interdependent. Online Appendix 2 is a summary of the recommendations.

\section{Independence}

The independence of a regulator is a key hallmark of regulatory effectiveness (Harrison, R. 2013; OECD 2014; 2016). In theory, regulatory independence

3 The Minister of Natural Resources does not define "modernization" in the Terms of Reference for the Expert Panel. Therefore, the author assumes that a "modern" regulator also means the regulator is effective and efficient.

4 Excellent and recent discussions on the attributes of regulatory effectiveness include publications by the Organisation for Economic Cooperation and Development (http://www.oecd.org/regreform) and the Alberta Energy Regulator's project on regulatory excellence in 2014/15, which was supported by the University of Pennsylvania's Penn Program on Regulation (https://www.aer.ca/about-aer/spotlight-on/regulatory-excellence-initiative).

5 The recommendations in this Commentary are relevant to NEB regulation of both pipelines and power lines. Care was taken in the development of these recommendations so as not to overlap with the Terms of Reference for the related recently released federal review of the environmental assessment process in Canada (the NEB is a Responsible Authority under the Canadian Environmental Assessment Act, 2012) as well as its review of changes to the Fisheries Act and Navigable Waters Protection Act. 
creates greater public confidence - decisions are made in an objective manner, without conflict of interest and free of undue influence (Harrison, $\mathrm{K}$. 2015; OECD 2014).

Independence relates to how the regulator functions with respect to its relationship with the political arm of government, as well as how it functions with respect to the influence of the industry it regulates. For the NEB, the extent of its independence from government is defined by Parliament in its enabling legislation (Government of Canada 2015). ${ }^{6}$

The NEB has three main functions.

1 Adjudicative: As a quasi-judicial tribunal, the NEB makes recommendations to cabinet and decisions on energy matters within its jurisdiction (See Box 1). Its adjudicative processes follow the rules of natural justice and are independent of political influence. ${ }^{7}$ As well, the NEB functions independently of the government in deciding how to carry out its hearing processes.

2 Regulatory: As a regulator, the NEB has oversight of the infrastructure under its jurisdiction throughout the asset's lifecycle (i.e., from construction to abandonment). The NEB can make and enforce conditions of approval and regulations governing the tolls and tariffs on energy infrastructure, as well as conditions related to environmental protection and the safety and rights of those affected by energy infrastructure.
3 Advisory: As an energy adviser, the NEB collects and publishes energy statistics and market information as well as information on the safety and security of pipelines and international power lines. The NEB can provide advice on matters within its jurisdiction to the minister, at the minister's request.

The NEB's regulatory and advisory functions do not typically follow quasi-judicial processes and are not always carried out independently of communication with the federal government, industry or other stakeholders. With respect to its regulatory function, the NEB is required to consult with the minister, industry and all other parties whose rights may be affected by a new regulation. As well, the NEB needs to communicate directly with industry when it is carrying out its compliance activities, including inspections, audits and any follow-ups to corrective action plans.

With respect to its advisory function, there are certain aspects it does not undertake unless asked by the minister. The transparency of the NEB's advisory function is discussed later in this Commentary under Transparent and Inclusive Processes.

The NEB also undertakes consultation with energy experts and interested stakeholders when preparing its energy-market-outlook information. ${ }^{8}$ Unless otherwise specified through a ministerial

6 Although the term "independent" does not appear in the NEB's enabling legislation, the Government of Canada recognizes that administrative tribunals such as the NEB make decisions at an "arm's length" from government using quasi-judicial processes (see Appendix H of Government of Canada, Open and Accountable Government).

7 Natural justice is defined by the NEB in the Frequently Asked Questions section of its website: https://www.neb-one. gc.ca/prtcptn/hrng/prtcptngdncfq-eng.html\#q4. "Generally, there are two components to the principles of natural justice and fairness. First, a party must have an adequate opportunity to be heard before a decision is made affecting that party's interest. The second component is that the decision must be made by an independent and impartial decision-maker. Among other things, the principles of natural justice require that a person be given an adequate opportunity to be heard before a decision is made affecting their interests. There still needs to be a sufficiently direct impact to trigger a natural justice right to participate. The content of the principles of natural justice and fairness will vary from case to case. Essentially, what is 'fair' requires a balance between what is necessary for the effective and efficient performance of public duties, as mandated under an empowering statute, and what is necessary for the protection of the interests of the parties affected."

8 A list of organizations consulted by the NEB for its "Canada's Energy Outlook 2013" is provided at http://www.neb-one. gc.ca/nrg/ntgrtd/ftr/2013/ppndcs/rprtmthdlg-eng.html. 
request, the NEB sets its annual agenda for energymarket-forecast publications, which typically follow a regular cycle.

While the federal government recognizes that the NEB undertakes its adjudicative function at arm's length, the NEB's ability to control its adjudicative processes shifted with the introduction of Bill C-38 (see Box 2 for details). The ensuing legislation changed the NEB's role as a decisionmaker for certain types of applications, provided cabinet mechanisms to override any NEB recommendation and changed how the NEB undertakes its hearings.

Specific changes included:

- For applications of pipelines greater than 40 kilometres in length, the NEB's role changed from making a final decision to making a recommendation to cabinet. ${ }^{9}$ Regardless of the recommendation, the NEB must now provide proposed terms and conditions for an approval (Minister of Justice 2016; see s.52 (1)(b)).

- Cabinet can now choose to accept the NEB's recommendation and proposed conditions, override the NEB's recommendation or send the recommendation back to reconsider its proposed terms and conditions.

- Prior to Bill C-38, the NEB would forward a decision to cabinet for consideration only if the application was approved. Cabinet could choose to confirm or reject the approval. However, if the NEB decided to not approve an application, the decision was final and not forwarded to cabinet. There was no mechanism to override an NEB decision to reject an application other than through the courts (Harrison R. 2013; Savage 2016).
Clearly, there has been political influence over the years in NEB panels' project decisions since the board was established in 1959. For example, Savage (2016) cites examples of the joint decisionmaking between the NEB and the federal government on Interprovincial Pipelines' (now Enbridge) original Line 9 project. ${ }^{10}$ The concerns over Bill C-38 relate to diluting NEB independence (i.e., from a decisionmaker to a recommendation maker), putting the responsibility for final decisions with cabinet, which could be influenced by political interests, and introducing mechanisms for cabinet to override an NEB recommendation and influence proposed terms and conditions that were arrived at through a quasi-judicial, evidence-based process bound by the rules of natural justice.

Critics of the previous federal government and some of the interviewees for this Commentary said these changes undermined the NEB's effectiveness as a credible regulator (Savage 2016; Quarmby, Lynne pers. comm.; Ruitenbeek pers. comm.). As one observer put it, the changes were a "blunt political interference (Harrison, R. 2013).”

Lastly, these changes are inconsistent with the Organisation of Economic Development's (OECD) principles for the good governance of regulators (2016). Regulators surveyed by the OECD confirmed the executive branch of government is unable to overturn the decision of an independent regulator except through a judicial process (OECD 2016).

9 Of particular relevance to this Commentary, the NEB makes recommendations and issues orders respectively pursuant to s. 52 and s. 58 of the NEB Act. Applications for projects under s. 52 are for pipelines longer than 40 kilometres, while s. 58 applications are for pipelines under 40 kilometres in length, as well as for pump stations, storage tanks, compressors, etc. In the remainder of this Commentary, when the author refers to a review or application under the $N E B$ Act, she is typically referring to those applications under s. 52 or s. 58 .

10 See Savage (2016) for an examination of the historical context and evolution of the NEB's decisionmaking role. 


\section{Box 2: What Changed as a Result of Bill C-38 in 2012? *}

Bill C-38, the Jobs, Growth and Long-Term Prosperity Act introduced by the Harper government in 2012 made several changes to the $N E B A c t$, as well as to other legislation. Here is a summary of the major changes.

\begin{tabular}{|c|c|c|}
\hline Topic & Before Bill C-38 & After Bill C-38 \\
\hline Decisionmaking & $\begin{array}{l}\text { The NEB could decide whether to approve a } \\
\text { project and would forward the decision to the } \\
\text { Minister of Natural Resources Canada/cabinet for } \\
\text { consideration and final approval. } \\
\text { An NEB decision to reject a proposal would } \\
\text { be final - it would not be sent to cabinet } \\
\text { for consideration or approval. There was no } \\
\text { mechanism to override an NEB rejection. }\end{array}$ & $\begin{array}{l}\text { The NEB issues a recommendation to the } \\
\text { minister/cabinet, even if it recommends rejection. } \\
\text { Cabinet can choose to accept the recommendation, } \\
\text { reject/override it or send it back to the NEB for } \\
\text { reconsideration. }\end{array}$ \\
\hline $\begin{array}{l}\text { Legislated } \\
\text { timelines }\end{array}$ & $\begin{array}{l}\text { There were no legislated timelines for an NEB } \\
\text { review. (In the eight-year period prior to 2012, all } \\
\text { NEB reviews were completed within } 15 \text { months, } \\
\text { with the exception of the Mackenzie Gas Project.) }\end{array}$ & $\begin{array}{l}\text { For certain applications, the NEB must make a } \\
\text { recommendation to cabinet within } 15 \text { months of } \\
\text { determining an application is complete. } \\
\text { - Cabinet then has three months to make its } \\
\text { decision. } \\
\text { These timelines can be extended by the NEB } \\
\text { Chair, the minister or cabinet. } \\
\text { The NEB Chair and the minister have } \\
\text { mechanisms to alter NEB review procedures. }\end{array}$ \\
\hline Participation & $\begin{array}{l}\text { - The NEB typically allowed all interested parties to } \\
\text { participate in a hearing. } \\
\text { The NEB Act required the NEB to consider the } \\
\text { objections of "any interested person." }\end{array}$ & $\begin{array}{l}\text { - The NEB must hear from any person who, in the } \\
\text { NEB's opinion, is directly affected. } \\
\text { The NEB may choose to hear from any person } \\
\text { who, in the NEB's opinion, has relevant } \\
\text { information or expertise. } \\
\text { The NEB typically collects information from } \\
\text { potential participants through an application } \\
\text { process before the NEB rules on participation. }\end{array}$ \\
\hline
\end{tabular}

\section{Recommendation 1}

The federal government should restore the functional and perceived independence of the NEB's decisionmaking authority for pipeline applications involving more than 40-kilometres of pipeline by:
- Requiring it to make a decision whether to approve such an application and then forwarding that decision to cabinet for consideration, and

- Removing any mechanism for cabinet to override such an NEB approval except through the Federal Court of Appeal.

- This recommendation should not be 
implemented in isolation of Recommendation 21 , which urges the creation of an integrated Canadian energy policy. Without the appropriate policy framework in which to make decisions, the NEB would not be well positioned to act in the public interest.

\section{Timeliness}

Timeliness is key to regulatory effectiveness and to the efficient use of resources in a review process (i.e., both internal regulator resources and those of the public who participate. Additional Bill C-38 measures affecting how the NEB undertakes its adjudicative process and, therefore, the efficient execution of its procedures and its ability to be master of its own process included:

- Mandatory timelines for the review of certain applications under the NEB Act (e.g., 15 months from the time an application is deemed complete to when a panel or the board must issue a recommendation or make a decision). As well, the changes provided extraordinary powers to the minister and the NEB chair to issue directives to alter review timelines.

- Allowing the NEB to determine who can participate in an NEB Act review. The NEB can now consider representations from those directly affected by an application or anyone the NEB deems has relevant information or expertise related to the application. Prior to this change, any interested person could participate in an NEB review.

The changes allowing the minister and chairperson to issue directives affecting a panel's procedure potentially intrude on a panel's procedural independence. However, these mechanisms have not been exercised to date (Harrison, R 2013; Savage 2016). In fact, when the panel reviewing the Trans Mountain Expansion Project requested two extensions, lengthening the 15-month review, both requests were granted.

The change legislating a mandatory timeline for certain NEB reviews has led to the perception among some observers that the integrity of the
NEB's review process has been eroded (Savage 2016). Mandatory time limits were introduced in Bill C-38 partly in response to the more than five years spent reviewing the controversial Mackenzie Gas Project, which had no mandatory timelines. (The Joint Review Panel for the review of the proposal to take natural gas from the Northwest Territories to southern markets was struck in August 2004 and delivered its report in December 2009.)

The question remains whether a mandatory and prescriptive timeline is the best tool to support regulatory effectiveness and, therefore, the efficiency of regulatory processes. Specifically, is a 15-month time frame appropriate for all types of applications under the $N E B A c t$, given that they vary in location, complexity and degree of public concern?

As well, the question remains whether the mandatory timelines are sufficient to allow the Crown to adequately fulfill its duty to consult Aboriginal people (see Recommendation 23). The Crown typically continues to carry out consultation on the NEB's recommendation, even after its report is released. However, three months postNEB-recommendation, as set out in the NEB Act, may not be sufficient in all cases for the Crown to adequately consult with all potentially affected Aboriginal communities and peoples before making a decision.

Lastly, given the prescribed time limits, a panel may feel compelled to select procedural steps that fit the timeline rather than being most appropriate for the review. On the other hand, a review process with a mandatory timeline, including off-ramps where necessary, provides a degree of procedural certainty for all parties involved in the process.

\section{Recommendation 2}

The federal government should rescind the onesize-fits-all time-limit requirements on NEB reviews and on the cabinet process. As well, it should remove the extraordinary powers of the NEB chair and the minister to alter a panel's timeline or make-up. To support an efficient 
regulatory process, the federal government should instead require each panel to determine the timeline for each review, depending on factors such as the nature and complexity of the project, the procedural steps selected and the number of interveners involved.

However, the federal government should retain provisions in the NEB Act and other enabling legislation allowing the board to determine who is eligible to participate based on the criteria of being directly affected and/or having relevant expertise related to the project under review.

These provisions align well with the goal of regulatory effectiveness and efficiency, allowing the NEB to focus its reviews on the rights and interests of those directly affected by a project as well as providing opportunity to incorporate the relevant expertise of interveners, as opposed to providing a forum for the discussion of issues outside of the NEB's jurisdiction.

\section{Recommendation 3}

The NEB should ensure that any timelines set for the review of an application, irrespective of whether they are legislated, are consistent with its Departmental Results Framework, which sets out the NEB's regulatory outcomes and support the efficient delivery of the regulatory process for all participants.

\section{Conflict of Interest}

Avoiding situations where a conflict of interest could arise is key to effective regulatory governance and is critical in building public credibility in the decisionmaking process (OECD 2014). Similarly, transparently and proactively addressing conflicts of interest when they arise is also critical to the credibility of a regulator and the regulatory framework (OECD 2014).

The NEB and the federal government have several mechanisms in place to prevent conflicts of interest and to counter against an apprehension of bias, including a Code of Conduct for NEB board members and one for staff, along with an overarching conduct policy for the entire government supported by Conflict of Interest Act provisions.

Although the NEB and the federal government have implemented many mechanisms to counter conflicts of interest and are clear on the process by which a potential conflict is investigated, they have not clarified how their processes have changed in light of events described above, specifically avoiding conflicts in the appointment of new board members and in meetings with external stakeholders.

Lastly, the NEB's Code of Conduct for its employees lacks a "cooling off" period or other requirements for new staff previously employed by a regulated company or by a consulting firm representing a regulated company. The Code of Conduct does, however, include provisions for former NEB staff accepting employment with a regulated company. While it is critical for NEB staff to have a solid understanding of the regulated industry, which may be obtained through education or by working for industry, it is equally important for the NEB to have mechanisms in place to avoid a real or perceived conflict of interest.

\section{Recommendation 4}

If it has not already done so, the NEB should ensure members of the public who are involved in a regulatory review and who are party to private meetings with board members, NEB executive, or NEB staff divulge any direct contractual or indirect sub-contractual arrangements they have with NEBregulated companies prior to the meeting.

\section{Recommendation 5}

If it has not already done so, the federal government should review and update its hiring process for temporary and permanent board members to ensure that nominees are not concurrently advising or providing evidence to an NEB-regulated company 
in a proceeding. If a new temporary or permanent board member has had past business relationships with NEB-regulated companies, this should be proactively and publicly disclosed in accordance with the Conflict of Interest Act.

\section{Recommendation 6}

To avoid a perception of bias, the NEB should update its Code of Conduct to include a requirement prohibiting new staff previously employed by a regulated company or by a consulting firm representing a regulated company from reviewing applications from that company for a period of time, such as one year. Furthermore, if new staff previously worked for a regulated industry on a specific project that is part of, or related to, a proceeding before the NEB, the new staff should be prohibited from advising the panel on the proceeding.

\section{Recommendation 7}

The NEB and the federal government should transparently clarify the consequences to any board member, NEB executive or staff if a conflict of interest has been found to occur; i.e., beyond those penalties set out in s.52 of the Conflict of Interest Act. (See the Alberta Energy Regulator's Conflict of Interest Policy and Procedures for options).

Related to conflict of interest, the concept of "regulatory capture" could result in an actual or perceived bias in decisionmaking. Regulatory capture is defined as the regulated industry manipulating the regulator or controlling regulatory outcomes (Dal Bó 2006).

There is a perception that the NEB is captured by the industry it regulates. For example this can be based on:

- The perception that board members' professional experiences are more representative of industry interests than of the broader public interest; ${ }^{11}$

- The perception that the NEB's process is a "rubber stamp," approving any application submitted by industry; ${ }^{12}$ or

- Concerns related to project-specific decisions made by a recent Panel (Eliesen 2014).

This overall perception is reinforced by:

- The NEB Act mandating the NEB's head office be located in Calgary, where many pipeline and other energy companies are headquartered. (Until 1991, the NEB's head office was located in Ottawa.)

- The NEB Act requiring that permanent board members "... reside in, or within a reasonable commuting distance of, Calgary, Alberta or at such other place in Canada as the Governor in Council may approve (section 3(5) of the NEB Act)."

It is difficult to measure the existence or extent of regulatory capture, since it is subjective to evaluate whether an NEB decision is in the interest of regulatory effectiveness or because the regulator is captured by the regulated industry. In certain cases, the NEB's decisions or actions result in good regulatory outcomes for many affected stakeholders, including the regulated industry.

What is important about regulatory capture is not necessarily determining whether it exists but ensuring there are transparent processes in place to guard against its existence. As well, the

11 See http://www.theglobeandmail.com/report-on-business/industry-news/energy-and-resources/national-energy-boardsuspends-future-hearings-into-energy-east-pipeline/article31610177.

12 A simple Google search of "NEB is a rubber stamp" revealed many links to articles, blogs and comments holding the opinion that the NEB's process is a "rubber stamp." Many of these opinion holders were also opposed to the expansion of the oil sands in Alberta and the federal government under Prime Minister Stephen Harper. 
federal government must play a role in preventing regulatory capture. Tools that can be helpful in avoiding regulatory capture include:

- Representing stakeholder interests at the staff and board levels. This could include staff and board members who have training or experience with landowner, Aboriginal, environmental, socioeconomic, economic, financial, engineering, safety, security and risk-assessment issues. For their part, the previous and current federal governments have addressed the lack of board diversity by hiring new members with an emphasis on skills or experiences that may not be currently represented (OECD 2013).

- Enabling the NEB to make decisions and recommendations that are in the public interest, with a policy framework reflective of that interest. To avoid regulatory capture, the policy framework, which is set by the federal government, must represent all aspects of the public interest.

- Ensuring the NEB has a coherent and transparent performance-management system. The expectations of regulatory performance must be applied consistently to all regulated companies. If regulatory capture existed, resulting in leniency toward regulated companies, it could translate into lower compliance and poorer regulatory performance (OECD 2013).

\section{Recommendation 8}

The federal government should examine whether it is necessary to mandate in legislation the location of the NEB's headquarters as well as the requirement for all permanent board members to reside in or near Calgary, Alberta. As well, the federal government should examine the opportunities and challenges with the NEB's headquarters located in Calgary, Alberta, ensuring that, where possible, the challenges associated with the location have been identified and addressed.

\section{Transparent and Inclusive Processes}

Several observers have explored the relationship between transparent and inclusive processes, as well as between regulatory effectiveness and efficiency (Coglianese and Shapiro 2015; External Advisory Committee on Smart Regulation 2004; Matthews et al. 2015; Nash and Walters 2015; OECD 2013; OECD 2014). Simply put, these authorities agree that transparent and inclusive processes result in better regulatory outcomes, as more robust information is available to decisionmakers, and openness enhances the legitimacy of a regulatory agency and its decisions.

For the NEB, this means ensuring that the processes supporting its three main functions are designed with transparency and inclusion as a priority. With respect to its adjudicative processes, the NEB has made substantial improvements in making its hearings more transparent and inclusive including:

- Developing and implementing a participant funding program;

- Providing a hearing process adviser to support potential participants with the application-toparticipate process, as well as to assist interveners and commenters with procedural information throughout a hearing process;

- Providing online webinars for interveners and commenters related to procedural steps such as writing motions, information responses, letters of comment and presenting evidence, among other things;

- Establishing a web page for each major proceeding with links on the NEB's home page;

- Providing a plain-language summary of its recommendations, where appropriate;

- Providing a written explanation of its recommendations and decisions (note, this has always been done); and

- Adapting its oral hearing proceedings to be culturally appropriate by including traditional Aboriginal ceremonies and providing for Aboriginal people to present evidence orally on traditional activities and knowledge, instead of in writing.

Still, criticisms related to the transparency of the NEB's adjudicative process remain. They include: 
- The perception that evidence was not adequately tested in the review of the Trans Mountain Expansion Project, since oral cross-examination was not included in the proceeding and evidence, when based on science, was not peer reviewed (Quarmby, Lynne pers. comm.; Allan, Robyn, pers. comm.).

- The perception that approval of the Trans Mountain Expansion Project was not based on all the facts as there was a dispute over the science related to the fate and behaviour of spilled diluted bitumen (Quarmby, Lynne pers. comm.). In this specific case, interveners Living Oceans Society and the Raincoast Conservation Alliance wanted to file new evidence approximately six months after the final deadline for evidence. The new evidence was a third-party draft report from the U.S. National Academy of Sciences on the fate and behaviour of spilled bitumen. In the end, the panel decided the value of including the new evidence did not outweigh the potential delay to the proceeding. ${ }^{13}$

- A claim that the analytical methods underpinning the need, economic feasibility and commercial impacts of the Trans Mountain Expansion Project were neither sufficiently robust nor comprehensive enough to support a positive recommendation (Allan, Robyn pers. comm.). As well, one interviewee noted it was inappropriate to use proprietary economic models in evidence, as interveners could not transparently test the assumptions and risks underlying the models (Allan, Robyn pers. comm.).

\section{Recommendation 9}

When there is a dispute over evidence, the NEB should identify and implement alternative hearing tools to allow for a robust examination, ensuring that the evidence is fact based. Alternative hearing tools could include a public technical conference within the proceeding, hiring a third-party to review the evidence and present findings on the hearing record, or allowing for oral crossexamination on certain evidence or issues.

\section{Recommendation 10}

As part of its ongoing review of the information required for facilities applications in the Filing Manual, the NEB should engage interested stakeholders in a discussion and review of the methodology for the economic analyses required in a facilities application.

\section{Recommendation 11}

The NEB should allow evidence based on the use of proprietary models only if the risks and assumptions of the model can be verified either through direct evidence, through verification by an independent third party, or as otherwise directed by the NEB.

With respect to its regulatory role, the NEB has been extremely active lately, engaging Canadians on a range of matters such as safety and emergency management (NEB 2015a). Recently, the NEB committed to improving the transparency of emergency management programs and to creating more opportunities to engage with local authorities on these matters. Some of the issues in the recent NEB review of the Trans Mountain Expansion Project and in the Energy East Pipeline Project included the role and capacity of local authorities in responding to an incident on an NEB-regulated facility in their communities and the accessibility of NEB-regulated companies' emergency management program information.

13 See the NEB's decision on the motion with links to interveners' input: https://apps.neb-one.gc.ca/REGDOCS/File/ Download/2896929. 
The NEB has also recently started to publicly post inspection reports and non-compliances on its website and continues to share audit reports and corrective action plans. As well, it has initiated an online tool showing where incidents have occurred on NEB-regulated facilities in Canada.

Given the potential for an increase of pipeline development in more populated areas including in Aboriginal communities, it would be well-timed to initiate an ongoing mechanism to engage communities outside of a formal hearing process. The NEB should continue to be mindful of including interested stakeholders in discussions of regulatory initiatives where their rights or interests may be affected by a change.

\section{Recommendation 12}

The NEB should implement a mechanism for ongoing public engagement, with an initial focus on local and Aboriginal communities affected by NEB-regulated facilities, on the range of issues under its mandate.

One potential model is a network of external advisory committees established on a topical and/ or regional basis (Leggett, Sheila pers. comm.). A representative from each advisory committee in the network would report to a chair's external advisory committee, providing ongoing input (Leggett, Sheila pers. comm.). Another model is the multistakeholder advisory committee recently launched by the Alberta Energy Regulator (AER 2017).

Meanwhile, as noted, the NEB engages with regulated companies on compliance requirements throughout the life of a regulated asset. These interactions include inspections and audits, among other activities. Interviewees from large pipeline companies indicated the NEB is not clear on its compliance expectations. They felt that measuring effectiveness of a management system on a binary, compliance-versus-non-compliance basis was not valuable, as the audit findings would not reflect the management system's maturity level or philosophy of continual improvement.

Companies also stated the content of the NEB's audit protocol appears to change from audit to audit and from company to company, opening the door for the perception of different treatments among regulated companies. Lastly, companies stated the clarity of the audit process and application of the audit protocol varied by NEB auditor.

\section{Recommendation 13}

The NEB should engage regulated industry in its efforts to update/revise its audit protocols in order to address issues related to clarity and consistency of compliance. The NEB's audit program should reflect best practices in management system audits and include audit protocols focused on compliance instead of on management-system effectiveness. Lastly, the NEB's audit program should be aligned with the NEB's Departmental Results Framework.

\section{Recommendation 14}

The NEB should invest in further staff training and development with the goal of increasing the quality and consistency of its audit methodology. It should also ensure it has a sufficient number of trained auditors to carry out its audit workload in a timely manner.

Lastly, with respect to the NEB's advisory function to the minister on an as-requested basis, the mechanism for ministerial requests is unclear. As well, under the NEB Act, the chair can provide unsolicited feedback to the minister on policy-related issues that may arise through the NEB's proceedings or elsewhere, though it is unclear whether this information must or can be made public.

\section{Recommendation 15}

To increase the transparency of information exchanged between the NEB and the minister, 
ministerial requests for policy-related advice should be made public at the time of the request. Similarly, all advice initiated by the NEB should be made public at the time it is provided to the minister.

Within its advisory function, the NEB also prepares and publishes energy-market information, which is often relied on by applicants when preparing economic analyses to meet the NEB's filing requirements. Some of the interviewees for this Commentary indicated there could be a real or perceived conflict of interest if one NEB department prepares energy-market information for an application while board members rely, even partially, on the NEB's own information (Allan, Robyn pers. comm.; Oleniuk, Terri-Lee pers. comm.).

The interviewees raised a few related issues. First, does the NEB undertake a rigorous and transparent review of its methodology for preparing its energymarket reports? Secondly, within a hearing process, are there sufficient opportunities for interveners to test the evidence that relies on the NEB's energymarket reports. Lastly, what motivation would a panel have to disagree with an economic analysis partly based on the NEB's own energy-market reports?

\section{Recommendation 16}

The federal government should examine whether a conflict of interest exists between the NEB's adjudicative and advisory roles. If no conflict is found, and the NEB retains both roles, the NEB should review its methodology for energy-market reports to ensure there is sufficient opportunity for interested stakeholders to test and provide input into the methodology.

\section{Performance Management and Adaptability}

An effective and efficient regulator discharges its tasks in a clear and transparent manner, by setting objectives, achieving outcomes, measuring performance and learning lessons (Baldwin 2015; Boothe 2013; Coglianese 2015; OECD 2008; OECD 2013; OECD 2014). Given the complexity of regulation and the public's increasing scrutiny of energy regulation, measuring performance is critical (Moynihan 2015; Quarshie, Elizabeth, pers. comm.). An effective and efficient regulator must be able to articulate what it does, how it does it and what it has achieved in order to demonstrate accountability, to identify where improvements could be made and to rationalize increased budgetary spending to support improvements (Moynihan 2015). As well, an effective and efficient regulator can avoid regulatory capture by transparently declaring the outcomes that all regulated players are expected to reach, the indicators by which they will be measured, as well as publicly sharing the results of its performance evaluations (OECD 2013).

The Treasury Board has a new Policy on Results which defines requirements for federal bodies such as the NEB to implement a performancemanagement system, called a Department Results Framework. ${ }^{14}$ Prior to this new policy, introduced in 2016, the NEB had various aspects of a performance-management framework in place. However, there was little logic linking the NEB's activities with its desired regulatory outcomes or in measuring how effective its activities were in achieving these outcomes. While the NEB is working to comply with the Treasury Board's Policy on Results, absent a coherent performancemanagement framework, it is missing an opportunity to tell the story of its effectiveness, potentially strengthening its credibility with stakeholders. 
An effective regulator is also one that evaluates its performance on a regular basis, identifies and implements improvements, and adapts to changing circumstances (Boothe 2013; Coglianese 2015; OECD 2014). The NEB uses the term "evaluation" in a variety of contexts, including when it refers to "audit/evaluations" of regulated companies' programs, as well as in reference to evaluations of its own programs. To date, it appears the NEB has undertaken only one formal evaluation of its performance, which was an evaluation of the Participant Funding Program, released in early $2016 .{ }^{15}$

\section{Recommendation 17}

Given that the NEB is developing a Departmental Results Framework, it has an opportunity to publicly share information on the logic of its performance-management framework including, for example, information linking the NEB's outcomes, targets, indicators and activities. Therefore, the NEB on an annual basis should publicly share its plan to evaluate programs.

\section{Recommendation 18}

The NEB should establish an independent body to evaluate its Departmental Results Framework to ensure neutrality in accordance with the Treasury Board Policy on Results. (One model for an independent evaluation function is that used by international financial institutions such as the Asian Development Bank or Inter-American Development Bank.)

\section{Recommendation 19}

The NEB should continue to publicly share the results of its formal evaluations, highlighting what specific improvements it will undertake.

\section{Capacity}

In order to attract and retain qualified and motivated employees, an effective and efficient regulator must have sufficient capacity to undertake its work (OECD 2008). As Coglianese (2015) notes, an excellent regulator demonstrates stellar competence by using its resources to maximize public value. It does this by ensuring its employees are highly skilled, have access to regular training, are sensitive to the varying cultures of the communities and individuals with whom they interact and are compensated at a level competitive with the regulated industry (Coglianese 2015).

The NEB has faced ongoing challenges to recruit and retain employees in certain job families (Office of the Auditor General 2015). As new pipelines are approved and new regulatory requirements are introduced (e.g., the new Pipeline Safety Act), the NEB's workload will increase in step to ensure compliance throughout the regulatory lifecycle. Based on its ongoing analyses of its human resources capacity, the NEB has identified an ongoing need for specialists in areas such as pipeline integrity management, safety management systems, emergency response, and environmental and regulatory compliance (Office of the Auditor General 2015). In particular, the NEB has faced ongoing challenges to attract and to retain employees in the areas of safety and

15 See the NEB's evaluation of its Participant Funding Program at http://www.neb-one.gc.ca/bts/pblctn/ vltns/2016pfpvltnrprt/index-eng.html\#s2. Also, the NEB posts the evaluations of its performance-management framework at: http://www.neb-one.gc.ca/bts/pblctn/vltns/index-eng.html. 
engineering because it competes with the regulated industry for the same people (Office of the Auditor General 2015). These ongoing challenges, if unmet, could undermine the NEB's ability to carry out compliance-verification activities and to achieve its regulatory outcomes.

The NEB has the ability to hire consultants to fill any capacity gaps it may have on a short-term basis. While it evaluates proposals from consultants on the basis of "best overall value," the bidder with the "lowest firm, all-inclusive per-diem rate" will receive the most points in the NEB's bid evaluation process (NEB 2017). While it is important to consider the cost effectiveness of bids, the lowestcost bidder might not be the most qualified. Based on this evaluation methodology, potential bidders may choose not to bid and instead seek more lucrative contracts elsewhere.

\section{Recommendation 20}

The federal government, with the cooperation of Treasury Board, should identify and remove all impediments to the NEB's hiring and contracting requirements so as to attract the most appropriate candidates for technical roles, as well as consultants for short-term contracts. Although cost must be a factor in selecting employees and contractors, it should not be a barrier to attracting and retaining experienced people.

\section{Enabling Factors}

An effective and efficient regulator may undertake many of its functions independently of the political arm of the government. However, it does not operate in a vacuum. A regulator could possess all the previously described attributes of regulatory effectiveness and efficiency and still not be effective, if certain factors outside of its control are missing.

For the NEB, two of those missing factors that hinder its ability to carry out its duties effectively and efficiently include:
- An integrated Canadian energy policy framework in which to make project-specific decisions that are said to be in the public interest (IEA 2015); and

- A consistent and legally sound process in which the Crown meets its constitutional duty to consult with Aboriginal people when that duty is triggered.

With respect to the former, the NEB makes adjudicative decisions/recommendations that are said to be in the public interest (Parliament of Canada 2016). In its Reasons for Decisions or recommendations to cabinet, the NEB typically outlines its "present and future public convenience and necessity test" and provides a rationale for its recommendation "in the overall Canadian public interest (NEB 2016b).” The challenges with the NEB's definition of the public interest and recommendation process are:

- The definition is vague and lacks reference to a policy framework that defines the direction and priorities for Canadian energy development. As a result, NEB decisions on a project-specific basis become the default policy direction for the aspects of energy development within its mandate.

- The only tool the NEB has to gauge the public interest in its proceedings is the evidence before it for a specific project. It has no other mechanism to measure the public interest or the change in the public interest "as society's values and preference evolve over time" within a specific proceeding or on an ongoing basis.

- The NEB does not actively recruit participants into its hearing processes. It facilitates the application process for potential participants with the criterion participants must meet, as set out in the NEB Act. What if no one applies to participate in a proceeding? Conversely, what if many people apply and the NEB must decide who can participate? Is the participation that results from either of these two scenarios an effective mechanism to support the NEB's decisions/recommendations in the public interest for a given project? 
While Natural Resources Canada is the federal department responsible for energy development and policy, the only reference to energy policy on its website is buried five levels down under "Energy $>$ Energy Resources $>$ Transportation Fuel Prices $>$ Energy Policy." Several observers and interviewees concurred that the federal government needs an energy policy framework within which the NEB could more effectively and efficiently carry out its mandate (Cleland et al. 2016; External Advisory Committee on Smart Regulation 2004; Gibbins and Roberts 2008; IEA 2015; Quarmby, Lynne pers. comm; Quarshie, Elizabeth pers. comm.).

Very often, participants in NEB reviews want to discuss policy-level issues that are outside of the NEB's mandate and scope of the review (Watson 2016). They become frustrated because they feel the NEB is inflexible and cannot accommodate policy discussions. Since there is no other forum in which the public can provide feedback to the federal government on policy issues such as climate change, greenhouse gas emissions from upstream/ downstream energy development and cumulative effects, these issues arise at NEB project-specific reviews.

The NEB was born out of the 1956 Great Pipeline Debate and two subsequent federal royal commissions when the question was, "Which pipeline development would be in the public interest?" not, "Would any pipeline development be in the public interest? (Savage 2016)."16 At the time, it was generally accepted that energy development was a good thing and that pipelines were needed. Fast forward to 2017 — the federal government has aspirations for a radical transformation of Canadian energy systems by 2030-2050, transitioning to a clean energy economy and meeting Canada's greenhouse gas emissions reduction targets set at the 2015 United Nations Climate Change Conference, COP21 (Cleland et al. 2016). These aspirations are at odds with the current context in which energy decisionmaking takes place because there is no coherent energy policy framework in which to guide project-specific decisions.

Building a Canadian energy strategy and engaging the public in this dialogue is a huge task. Still, Canada appears to be moving toward creating such a strategy (Council of the Federation 2015; IEA 2015; Government of Canada 2016b). An effort in 2015 by the provinces kick-started the dialogue, although the federal government was largely absent from these discussions (Council of the Federation 2015). Most recently, Canada's First Ministers announced details of a Pan-Canadian Framework on Clean Growth and Climate Change that focuses on the links among greenhouse gas emissions, climate change and energy use. However, this most recent policy announcement is still a long way from providing policy direction that defines the direction and priorities for Canadian energy development

It will take time, money, human resources and creativity to determine how best to engage a heterogeneous public on a range of issues related to energy development overlapping with Aboriginal rights and interests, climate change, transportation (including alternative methods of transporting hydrocarbons), urban planning, taxation and trade policy, just to name a few. A dialogue will not guarantee that everyone will be happy with the outcome. However, the benefits could be significant and are relevant to the current Expert Panel Review of NEB Modernization.

With a credible, publicly supported national energy strategy, the NEB's project-specific decisions (see Recommendation 1 ) would likely have more

16 For a description of the Great Pipeline Debate, the Gordon and Borden Commissions and the related events from 1956 to 1959 leading to the creation of the National Energy Board, see Harrison (2013). 
credibility because they would be made within a policy framework reflective of the public's interests. As a result, projects that are deemed to fit within this policy framework could proceed. Understanding what types of energy development projects are acceptable within the policy framework provides a clear signal to industry and investors that there are opportunities to bankroll Canada's energy sector.

\section{Recommendation 21}

The federal government, through the minister of natural resources, should continue the public dialogue about an integrated Canadian energy strategy it started with the Pan-Canadian Framework on Clean Growth and Climate Change. The outcome would be a transparent energy policy framework, providing the foundation on which the NEB and other energy regulators could make decisions.

Although the minister is in the best position to decide how to engage stakeholders, one mechanism of engagement could involve establishing working groups across Canada to engage in a constructive dialogue, expanding on a recommendation in Eyford (2015; pages 42-43) and the mechanism used in the development of the framework. Representatives in these working groups could include, for example, Aboriginal leaders, federal and provincial representatives, representatives from local authorities, landowners and industry.

With respect to the Crown's duty to consult, the federal government relies on the NEB's hearing process to the extent possible to discharge its legal duty to consult potentially affected Aboriginal people (Government of Canada 2016a; NEB 2016b). The Major Projects Management
Office (MPMO) is the federal body tasked with coordinating various federal agencies' participation in NEB reviews for major projects. The NEB, however, makes many decisions unrelated to major projects that could affect potential or established Aboriginal and treaty rights and which trigger the Crown's duty to consult. In these cases, the Crown is absent from the process as the NEB does not act as the Crown.

In these cases, who is the Crown and how is its duty to consult met? These questions are the subject of two court cases currently before the Supreme Court of Canada. ${ }^{17}$ While the outcome of these cases will likely provide some clarity about the role of the NEB and the NEB's process with respect to the Crown's duty to consult, there would still be uncertainty about the NEB's process and decisions when the Crown is not present

Meanwhile, the courts have no issue quashing cabinet decisions on NEB projects where they found the Crown had failed in its duty to consult (Federal Court of Appeal 2016). This level of procedural and legal uncertainty may prove difficult for regulated companies and investors to manage and seems contrary to the spirit of governmentAboriginal reconciliation.

\section{Recommendation 22}

While waiting for clarity from the Supreme Court of Canada, the federal government should provide clarity about the roles and process to support the Crown's duty to consult for NEB processes when the MPMO is not involved.

To follow up on the issue of legislated timelines for the NEB's review process discussed earlier in this paper (see Independence), the MPMO carries out

17 See Chippewas of the Thames v. Enbridge Pipelines Inc. et al. (http://www.scc-csc.ca/case-dossier/info/mal-mdaa-eng. aspx?cas=36776) and Hamlet of Clyde River et al. v. Petroleum Geo-Services Inc. et al. (http://www.scc-csc.ca/case-dossier/ info/mal-mdaa-eng.aspx?cas=36692). 
certain consultation activities after the NEB releases its recommendation report. The legislated timeline between the NEB's recommendation and cabinet's decision is three months, though cabinet can extend this timeline. In practice, the cabinet timeline was extended to seven months for the Trans Mountain Expansion Project and to six months for the Energy East Pipeline Project to allow the Crown more time to consult with Aboriginal communities and people (Natural Resources Canada 2016).

\section{Recommendation 23}

In conjunction with Recommendation 2, the federal government should remove legislated time limits to carrying out its duty to consult Aboriginal peoples by removing the mandatory time limit in the $N E B$ Act for cabinet to review NEB recommendations and make a decision, while still respecting the efficient use of time and resources in the regulatoryreview process.

\section{CONCLUSIONS}

The answer to the question "Is the NEB broken?" is, "It depends on how you see the situation." For the interviewees of this Commentary, opinions varied widely about whether the NEB is fatally flawed or whether it needs to undertake a few improvements. What was commonly acknowledged, though, is that change in energy regulation and decisionmaking needs to happen.
It is in the shared interest of all Canadians to have trust in institutions whose decisions will shape the next steps in Canada's energy future (Cleland et al. 2016). The work of a regulator such as the NEB is difficult, complex and often thankless. Effective and efficient regulatory institutions are a necessary part of a functioning democracy. While regulators are not elected officials, they do the work delegated to them by elected politicians. Ideally, a policy framework should guide their decisions.

For the NEB to function as an effective and efficient regulator, its recommendations and decisions need to be guided by a transparent policy framework for energy development that is reconciled with the many other aspects of the public interest. The path to this framework will not be easy and not everyone will agree on the outcomes. However, the work is necessary to re-establish the NEB as a credible, effective and efficient energy regulator.

Lastly, it is important for the federal government to consider the outcomes of the simultaneous federal reviews to support the broader goal of improving the effectiveness and efficiency of federal energy regulation in Canada. ${ }^{18}$ This goal cannot be met by considering the outcome of each review in isolation, potentially creating duplication or overlap of regulatory processes and mandates.

18 The Terms of Reference for NEB Modernization: Expert Panel state: “In addition to Natural Resources Canada's efforts to modernize the NEB, Environment and Climate Change Canada is working to review environmental assessment processes under the Canadian Environmental Assessment Act, 2012. Also, the Departments of Fisheries, Oceans and the Canadian Coast Guard and Transport are working together to review changes to the Fisheries Act and Navigable Waters Protection Act, restore lost protections, and incorporate modern safeguards. In preparing for and undertaking the review, the Panel shall take into account the activities associated with the other mandated reviews, with the objective of sharing information received during the respective reviews, where relevant, and coordinating review activities, to the extent possible."

(Government of Canada 2016c). 


\section{REFERENCES}

Alberta Energy Regulator (AER). 2017. Alberta Chamber of Resources, Annual General Meeting. Speech by Jim Ellis, President and CEO of the Alberta Energy Regulator. Feb. 3, 2017. Speech available at: https://www.aer.ca/documents/aboutus/CEO_AlbertaChamberofResources.pdf.

Baldwin, Robert. 2015. Regulatory Excellence and Lucidity. Penn Program on Regulation. University of Pennsylvania Law School. Philadelphia.

Boothe, Paul. 2013. "Making Good Regulations." Canadian Public Policy, Volume XXXIX (3). 2013.

Cleland, Michael, Laura Nourallah, and Stewart Fast. 2016. "Fair Enough: Assessing Community Confidence in Energy Authorities." Canada West Foundation and the University of Ottawa. April.

Cleland, Michael, et al. 2016. A Matter of Trust: The Role of Communities in Energy Decision-Making. Canada West Foundation and the University of Ottawa. November.

Coglianese, Cary. 2015. Listening, Learning, Leading, A Framework for Regulatory Excellence. Alberta Energy Regulator and the Penn Program on Regulation.

Coglianese, Cary and Shari Shapiro. 2015. "Summary Report: Alberta Dialogue on Regulatory Excellence.” Rapporteur's Report from the Penn Program on Regulation, Alberta Dialogue on Regulatory Excellence.

Colton, John, et al. 2016. “Energy Projects, Social License, Public Acceptance and Regulatory Systems in Canada: White Paper." School of Public Policy Research Papers, Volume 9 (20). University of Calgary. May.

Council of the Federation. 2015. Canadian Energy Strategy. July.

Dal Bó, Ernest. 2006. "Regulatory Capture: A Review." Oxford Review of Economic Policy, 22 (2). 2006.

Eliesen, Marc. 2014. Letter of Withdrawal. National Energy Board Trans Mountain Expansion Project Proceeding OH-001-2014. Filing ID A4E1Q6. Accessed at: https://apps.neb-one.gc.ca/ REGDOCS/Item/View/2543157.
Eyford, Douglas R. 2013. Forging Partnerships, Building Relationships, Aboriginal Canadians and Energy Development. Report to the Prime Minister. Natural Resources Canada.

External Advisory Committee on Smart Regulation. 2004. "Smart Regulation: A Regulatory Strategy for Canada. Report to the Government of Canada."

Federal Court of Appeal. 2016. 2016 FCA 187.

Gibbins, Roger, and Kari Roberts. 2008. “Canada's Power Play. The Case for a Canadian Energy Strategy for a Carbon-Constrained World." Canada West Foundation. September.

Government of Canada. 2016. The National Energy Board Act. Current to December 8, 2016. Accessed at: http://laws-lois.justice.gc.ca/PDF/N-7.pdf. 2015. Open and Accountable Government. Accessed at: http://pm.gc.ca/ eng/news/2015/11/27/open-and-accountablegovernment.

Consultation and Accommodation Report for the Trans Mountain Expansion Project. November. . 2016b. Pan-Canadian

Framework on Clean Growth and Climate Change. Accessed at: https://www.canada.ca/en/services/ environment/weather/climatechange/pan-canadianframework/introduction.html\#1_1. 2016c. Terms of Reference, National Energy Board Modernization: Expert Panel. November 8, 2016. Accessed at: http://www. neb-modernization.ca/terms-of-reference

Harrison, Kathryn. 2015. "Regulatory Excellence and Democratic Accountability.” Penn Program on Regulation. University of Pennsylvania Law School. Philadelphia.

Harrison, Rowland. 2013. "Regulatory Independence and the National Energy Board: The Elusive Goal of Regulatory Independence and the National Energy Board: Is Regulatory Independence Achievable? What Does Regulatory Independence Mean? Should We Pursue It?" Alberta Law Review, 50(4). 
International Energy Agency (IEA). 2015. "Energy Policies of IEA Countries: Canada, 2015 Review.” Paris.

Matthews, Lesley, Jason Smith, and Sheila Leggett. 2015. "The Role of Public Engagement in the Regulatory Review of Linear Infrastructure Projects: Best in Practice and Potential Improvements. In: Environmental Concerns in Rights-of-Way Management." $11^{\text {th }}$ International Symposium. Utility Arborist Association.

Moynihan, Donald. 2015. "Performance Principles for Regulators.” Penn Program on Regulation. University of Pennsylvania Law School. Philadelphia.

Nash, Jennifer, and Daniel Walters. 2015. "Public Engagement and Transparency in Regulation: A Field Guide to Regulatory Excellence." Penn Program on Regulation. University of Pennsylvania Law School. Philadelphia.

National Energy Board. 1988. "Improving the Regulatory Process: Current Position on Submitters' Suggestions." Calgary. . 2014. Ruling No. 14 - Notice of Motions from Ms. Robyn Allan and Ms. Elizabeth May to include cross-examination of witnesses, Trans Mountain Expansion Project. May 7, 2015. Accessed at: https://apps.neb-one.gc.ca/ REGDOCS/File/Download/2453205. 2015a. "National Engagement Initiative Report: Engaging Canadians on Pipeline Safety." 2015b. "Striking of Evidence." Prepared by or under the Direction of Steven J. Kelly and postponement of oral summary argument in Calgary and Burnaby. Aug. 21, 2015. Accessed at: https://apps.neb-one.gc.ca/REGDOCS/File/ Download/2813274. .2016a. "National Energy Board: Mandate and Role under the CEAA." 2012. Presentation to the Expert Panel Reviewing Federal Environmental Assessment (EA) Processes. September 9. 2016. Accessed at: http:// eareview-examenee.ca/wp-content/uploads/ uploaded_files/2-neb_dm_prod-948723-ea-reviewpanel-presentation-neb-mandate-and-role-underceaa-2012-english.pdf. Report: Trans Mountain Expansion Project.” May 2016. 2016c. National Energy Board Ruling No. 28 - Panel Recusal and Adjournment of Hearing 002-2016 Energy East and Eastern Mainline. September 9, 2016. Accessed at: https://apps.neb-one.gc.ca/REGDOCS/File/ Download/3052021.

Plans and Priorities.

$$
\text { 2016d. 2016-2017 Report on }
$$

. 2016e. "NEB Corrective

Actions in Response to Office of the Auditor General Audit, Fall 2015 Report of the Commissioner of the Environment and Sustainable Development, Oversight of Federally Regulated Pipelines." From: www.neb-one.gc.ca/bts/pblctn/ dtrrprtndnbfnnclsttmnt/nbrspns2016-eng.html.

Report 2015-2016.

$$
\text { .2016f Departmental Performance }
$$

$$
\text { . 2017. "Request for Proposal }
$$
Emergency Management Training. Solicitation No. 16-0238."

Natural Resources Canada. 2016. "Interim Measures for Pipeline Reviews.”Jan. 27, 2016. Accessed at: http:// news.gc.ca/web/article-en.do?nid=1029989. 
Organisation for Economic Cooperation and Development. 2008. "OECD Guiding Principles for Regulatory Quality and Performance.” Paris. Oct. 29.

2013. "Public Consultation on Best Practice Principles for Regulatory Enforcement and Inspections." Draft Report Submitted to the Public for Comment. Paris.

Principles on Regulatory Policy. The Governance of Regulators." Paris. February.

Regulator. The Governance of Regulators.” Paris.

Office of the Auditor General. 2015. "Fall 2015: Reports of the Commissioner of the Environment and Sustainable Development. Report 2: Oversight of Federally Regulated Pipelines." Ottawa.

Office of the Prime Minister. 2015. "Minister of Natural Resources Mandate Letter.” Nov. 4, 2015. Accessed at: http://pm.gc.ca/eng/minister-natural-resourcesmandate-letter.

Parliament of Canada. 2016. "Proceedings of the Standing Senate Committee on Transport and Communications: Issue No. 5 - Evidence.” Sept. 21, 2016, morning.

Savage, Sonya. 2016. "Bill C-38 and the Evolution of the NEB: The Changing Role of the NEB from 1959-2015." CIRL Occasional Paper No. 52. Canadian Institute of Resources Law.
Taber, Jane. "PM Brands Canada an 'Energy Superpower'." The Globe and Mail. July 15, 2006. Accessed at: http://www.theglobeandmail.com/ news/world/pm-brands-canada-an-energysuperpower/article1105875/.

Watson, Peter. 2016. Letter to Johanne Gelinas, Chair Expert Panel on the Review of Environmental Assessment Processes. Dec. 14, 2016.

Zilnik, Dan, and Jason Switzer. 2015. "Deconstructing Keystone XL.” Corporate Knights, posted on Aug. 5, 2015. Accessed at http://www. corporateknights.com/channels/utilities-energy/ deconstructing-north-americas-contested-pipelineproject-14387400/.

\section{PERSONAL COMMUNICATIONS}

Allan, Robyn. Jan. 3, 2017.

Leggett, Sheila. Dec. 15, 2016. Tower Peak Consultants.

Oleniuk, Terri-Lee. Dec. 8, 2016. Osler, Hoskin \& Harcourt LLP.

Quarmby, Dr. Lynne. Dec. 14, 2016. Simon Fraser University.

Quarshie, Elizabeth. Dec. 22, 2016. Vice-Chair, Worker's Compensation Appeals Board.

Ruitenbeek, Jack. Dec. 9, 2016. H.J. Ruitenbeek Consultants. 
NOTES: 


\section{ReCEnt C.D. Howe institute Publications}

May 2017 Church, Jeffrey. Defining the Public Interest in Regulatory Decisions: The Case for Economic Efficiency. C.D. Howe Institute Commentary 478.

May 2017 Robson, William B.P., and Alexandre Laurin. "Premium Compensation: The Ballooning Cost of Federal Government Employees.” C.D. Howe Institute E-Brief.

avril 2017 Busby, Colin, Aaron Jacobs, et Ramya Muthukumaran. Besoin d'un rappel? Comment améliorer la couverture vaccinale des enfants au Canada. Institut C.D. Howe commentaire 477.

April 2017 Busby, Colin, Aaron Jacobs, and Ramya Muthukumaran. In Need of a Booster: How to Improve Childhood Vaccination Coverage in Canada. C.D. Howe Institute Commentary 477.

April 2017 Robson, William B.P., and Colin Busby. Numbers You can Trust? The Fiscal Accountability of Canada's Senior Governments, 2017. C.D. Howe Institute Commentary 476.

April 2017 Robins, Steven. "Surge Capacity: Selling City-owned Electricity Distributors to Meet Broader Municipal Infrastructure Needs.” C.D. Howe Institute E-Brief.

April 2017 Brown, Robert L., and Shantel Aris. Greener Pastures: Resetting the Age of Eligibility for Social Security Based on Actuarial Science. C.D. Howe Institute Commentary 475.

March 2017 Schwanen, Daniel, and Aaron Jacobs. Patents, Copyright and Competition: Assessing the Impact of Trade Deals on Canada. C.D. Howe Institute Commentary 474.

March 2017 Dachis, Benjamin. New and Improved: How Institutional Investment in Public Infrastructure can Benefit Taxpayers and Consumers. C.D. Howe Institute Commentary 473.

March 2017 Robson, William B.P., Aaron Jacobs, and Benjamin Dachis. "Equipment Failure: Feeble Business Investment Costs Canadians their Competitive Edge.” C.D. Howe Institute E-Brief.

mars 2017 Oschinski, Matthias et Rosalie Wyonch. Le choc du futur? Les répercussions de l'automatisation sur le marché du travail au Canada. Institut C.D. Howe commentaire 472.

March 2017 Oschinski, Matthias, and Rosalie Wyonch. Future Shock? The Impact of Automation on Canada's Labour Market. C.D. Howe Institute Commentary 472.

March 2017 Krane, Joshua, and Brian Facey. "Promoting Innovation and Efficiency by Streamlining Competition Reviews.” C.D. Howe Institute E-Brief.

\section{SUPPORT THE INSTITUTE}

For more information on supporting the C.D. Howe Institute's vital policy work, through charitable giving or membership, please go to www.cdhowe.org or call 416-865-1904. Learn more about the Institute's activities and how to make a donation at the same time. You will receive a tax receipt for your gift.

\section{A REPUTATION FOR INDEPENDENT, NONPARTISAN RESEARCH}

The C.D. Howe Institute's reputation for independent, reasoned and relevant public policy research of the highest quality is its chief asset, and underpins the credibility and effectiveness of its work. Independence and nonpartisanship are core Institute values that inform its approach to research, guide the actions of its professional staff and limit the types of financial contributions that the Institute will accept.

For our full Independence and Nonpartisanship Policy go to www.cdhowe.org. 

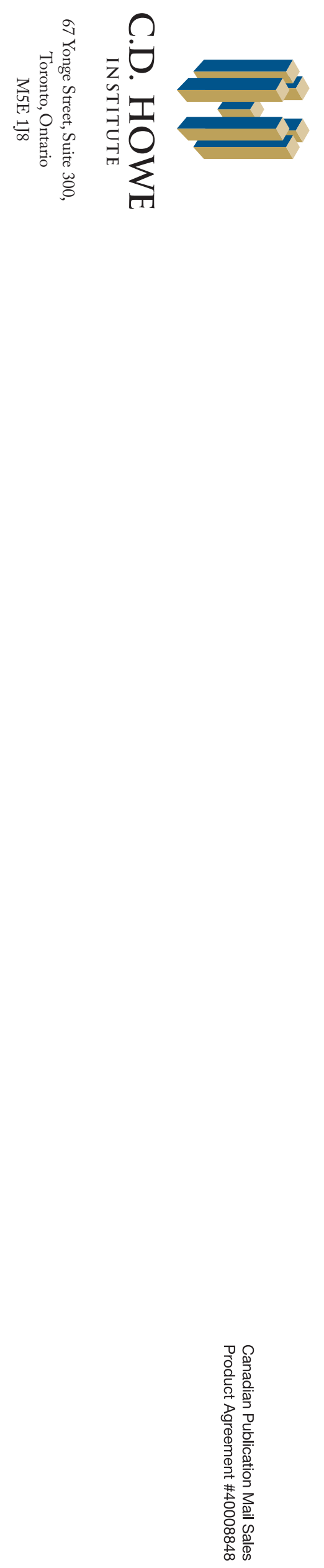